\title{
Towards an Ecological Perspective on Age-Performance Relations
}

\author{
Rui Mata ${ }^{1}$ and Ralph Hertwig ${ }^{2}$ \\ ${ }^{1}$ Department of Psychology, University of Basel, Switzerland \\ ${ }^{2}$ Max Planck Institute for Human Development, Berlin, Germany
}

\begin{abstract}
The layperson's view associates aging with biological and cognitive losses, which could be associated with decrements in work productivity and overall contributions to society. In turn, ecological approaches to life span development suggest that successful performance can result from an adaptive employment of an individual's physical, cognitive, or social capital in the appropriate environment. This ecological framework suggests that one must understand the demands of particular ecologies (i.e., niches) to predict whether aging is associated with failure, maintenance, or even improvements in performance. We provide examples that illustrate the importance of an ecological approach to understanding adaptation to challenging decision tasks both in the laboratory and in the wild. Overall, we propose that there are specific strategies and niches that can help older adults thrive and that more work is needed to understand the exact characteristics that lead to good performance in old age.
\end{abstract}

Keywords: adaptation, strategy, niche, selection, aging

Hunting is a difficult activity that human beings have had to conduct throughout their evolutionary past. Perhaps nowhere is the diversity of challenges posed by hunting greater than those found in the Amazon Jungle, which is home to thousands of different animal species, some of which are highly prized by the human foragers that inhabit it. Species vary in how easy they are to detect and capture, with some requiring great skill and experience for a successful kill. Capuchin monkeys, for example, live in small groups and spend most of their lives atop of trees so that human hunters must undergo complex maneuvering amidst dense vegetation to manage a shot using guns or bows from the ground below. Complex skills as well as strength seem necessary for killing monkeys because there is a late peak in performance with hunters in their 40 s doing best and with kill rates declining steadily with increased aging after that (Gurven, Kaplan, \& Gutierrez, 2006; Walker, Hill, Kaplan, \& McMillan, 2002). Other mammals such as the Agouti paca are solitary and nocturnal. Pacas' whereabouts are predictable because they prefer living near water, dig burrows with often only one exit, and use urine and anal glands to mark their territories. Dogs can be used to great effect in finding Agouti pacas, and hunters will often kill pacas by hand with no need for complex tool use. Most likely as a result of such task characteristics, the kill rate of Agouti pacas increases throughout the life span with no visible age-related decline (Gurven et al., 2006). These examples attest that the type of challenge (prey) can be crucial in moderating the effect of aging on (hunting) performance. We suggest that the two prey types can be thought of as two different niches that vary in their ageperformance relation: While success in hunting Capuchin monkeys shows a marked inverted-U shaped pattern across the life span, success in hunting the Agouti paca improves linearly with increased age. Crucially, the differential efficacy of younger and older individuals across such niches seems to contribute to the differences in effort and time spent on different activities (Gurven \& Kaplan, 2006). In other words, this example attests to how individuals of different ages can adapt by engaging in niche selection as a way to maximize their returns. In this paper, we discuss how such selection processes are key drivers of adaptation and successful performance across the life span.

Understanding the impact of aging on human behavior and performance may never have been more important. The last 150 years have been a time of major demographic changes, with steadily increasing life expectancy in many countries (Oeppen \& Vaupel, 2002), and projections suggest increased global population aging ahead (Lee, 2011). Such demographic trends have instigated questions concerning possible societal consequences, for example, regarding the sustainability of generous welfare states 
(Crimmins \& Beltran-Sanchez, 2010; Sanderson \& Scherbov, 2010). The impact of aging on societies depends partly on whether aging leads to decrements in productivity and other relevant outcomes. Attitudes to aging and the aged are mixed but the modal view associates aging with decrements in performance in a number of domains, including physical performance and cognitive ability (North \& Fiske, 2012). Likewise, there is evidence of aging being associated with physical (Tanaka \& Seals, 2007), neurological (Hof \& Morrison, 2004), and cognitive decline (Salthouse, 2009). But do age-related changes in ability necessarily lead to decrements in performance?

The foraging example presented above suggests that the impact of aging on performance may depend crucially on the problem at hand. We use the term performance as an umbrella term that can characterize desired outcomes in many domains, from foraging success to work productivity. The goal of this paper is to explore how an ecological perspective can help understand the range of age-performance relations across such various domains. In particular, we argue that one must understand the demands of particular ecologies to predict whether aging will lead to a decrement, maintenance, or even improvement in performance. The rationale for wanting to describe the form of age-performance relations is that knowing the exact circumstances leading to adaptation may be key to the efficient allocation of resources, for example, when deciding about the assignment of personnel to particular tasks, their remuneration, or retirement. We illustrate these points by showing how an ecological approach can help understand the performance of aging decision makers in a number of domains, from the laboratory to the workplace.

\section{The Ecological Perspective on Age-Performance Relations}

"To assert that human development is a product of interaction between the growing human organism and its environment is to state what is almost a commonplace in behavioral science (...). One would therefore expect psychology, defined as the science of behavior, (...) to investigate the person and the environment, with special attention to the interaction between the two. What we find in practice, however, is a marked asymmetry, a hypertrophy of theory and research focusing on the properties of the person and only the most rudimentary conception and characterization of the environment in which the person is found." (Bronfenbrenner, 1979, p. 16).
There is a tradition of using ecological approaches to understand life span changes in human behavior (S.-C. Li, 2003) and parallel approaches in closely related disciplines such as epidemiology (Satariano, 2006), social work (Greenfield, 2012), and human factors (Charness, 2008). The main commonality between these approaches is that they aim to understand performance as the result of the individuals' adaptation to their ecology. In particular, they emphasize the person-environment fit in determining physical and intellectual performance. Nevertheless, Urie Bronfenbrenner's complaint of an overabundance of theory and research on person characteristics and a relative neglect of the environment seem to still be accurate 30 years on. For example, a recent review of research on human judgment and decision-making proposes as the big challenge for future research the development of a systematic theory of "both the core capacities and environmental structures these exploit" (Gigerenzer \& Gaissmaier, 2011). In other words, it appears that researchers today are still grappling with the issue of how to best describe and predict the relation between person and environment.

A number of models have tried to capture the general interplay between the life span development of human capital and task demands (Diamond, 1984; Gurven \& Kaplan, 2006; Simonton, 1997; Skirbekk, 2008). All these models suggest that life span changes in various individual characteristics can have differential performance effects depending on task characteristics. Figure 1 depicts such a generalized version of such models that assumes only two sources of individual variation as well as two tasks/ environments. Figure 1A shows two distinct factors that vary across the life span which can be thought of as abilities, skills, or knowledge. The figure depicts the age gradient of the two abilities: While one ability, $a_{1}$, peaks rather early in the average life span, the other, $a_{2}$, peaks later. Perhaps a good example of factors with such distinct life span patterns is fluid and crystallized intelligence (Baltes, Staudinger, \& Lindenberger, 1999), but many other abilities or skills could be considered (e.g., Skirbekk, 2008). But how do these agerelated changes in abilities translate into task performance? The answer depends crucially on the task. To the extent that a task taps mostly or singly into the early-peaking ability, $a_{1}$, the performance curve for that task, $p_{1}$, will emulate the age distribution of that same ability. In contrast, to the extent that a task taps into the two abilities, $a_{1}$ and $a_{2}$, equally, the performance on that task, $p_{2}$, will show a delayed peak-performance relative to the former. The critical point is that the effects of basic abilities cannot be understood or assessed independently of task demands.

The models discussed above support an ecological approach that emphasizes the fit between person and environment characteristics but do not specifically address the processes by which individual adaptation occurs. 
(A)

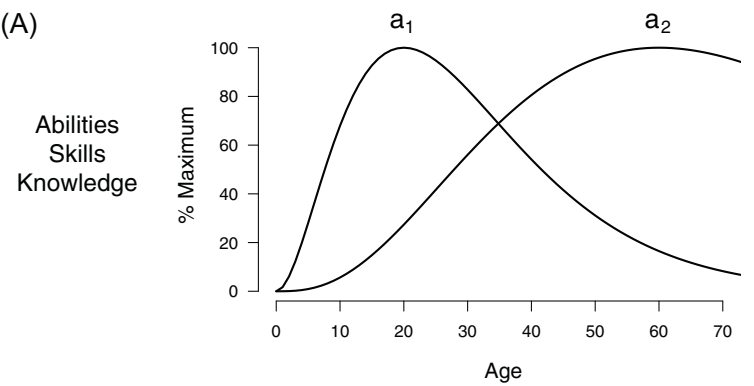

(B)

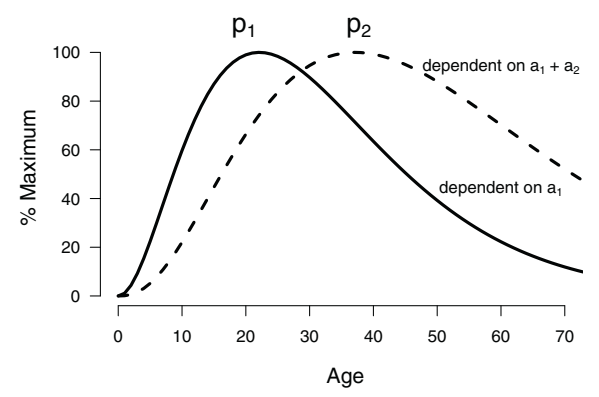

Figure 1. Illustration of the link between abilities and performance as a function of age. (A) the hypothetical age gradients for two different factors (i.e., abilities, skills, knowledge) modeled by functions of the form $a_{i}($ age $)=\operatorname{age}^{\alpha_{i}} e^{\beta_{i} \text { age }} ; a_{1}$ represents an early peaking ability (e.g., fluid intelligence) and $a_{2}$ a late peaking ability (e.g., crystallized intelligence). (B) task performance for two tasks that differ in the demands put on $a_{1}$ and $a_{2}$, which can be modeled by using different weights, $w$, for a given ability, $i$, and task, $j$, in a Cobb-Douglas production function of the form $p_{t}($ age $)=\prod a_{i}(\text { age })^{w_{i t}}$; while one task (solid line) taxes mostly $a_{1}$, the second (dashed line) taxes both $a_{1}$ and $a_{2}$, which results in the latter showing a delayed peak performance relative to the former.

Past research emphasizes the proactive role of individuals and suggests at least two main selection processes that are at play when individuals adapt their behavior in order to maximize performance (see Table 1).

First, individuals may rely on strategy selection; that is, select strategies adaptively as a function of their own abilities and environmental challenges. The notion of ecological rationality conceptualizes adaptive behavior as the result of a fit or match between the capabilities of the human mind and the characteristics of the environment. In turn, the concept of strategy provides the mediating mechanism between individuals' capabilities and specific environments (Marewski \& Schooler, 2011). Strategies can be defined as sequences of operations or processes aimed at accomplishing a task, and the strategy concept has been used in many domains, including memory and arithmetic (Lemaire, 2010), and decision making (Payne, Bettman, \& Johnson, 1993). Crucially, according to the ecological perspective, each strategy may be seen as occupying or fitting a particular niche (Marewski \& Schooler, 2011); consequently, given a toolbox or repertoire of strategies available to individuals, it becomes crucial to adaptively select a strategy that suits the specific niche best. Past research on aging that has adopted the ecological rationality perspective suggests that aging is characterized by some changes in strategy selection, with older adults relying on simpler strategies to better deal with the challenges faced due to age-related cognitive decline; nevertheless, results suggest that strategy selection remains largely adaptive across the adult life span in the sense of being responsive to task characteristics (for reviews see, Lemaire, 2010, and Mata, Pachur, et al., 2012). The idea that individuals select and shape the strategies adaptively to deal with challenges has also been independently proposed in more applied areas, such as in the occupational domain (Kooij, Tims, \& Kanfer, 2014).

Second, individuals may rely on niche selection; that is, select the environments or niches they choose to tackle in the first place. The concept of niche can be helpful in understanding the link between individuals' characteristics and the goals they pursue: Individuals can be thought to seek (or be selected into) those niches that best match their skills, just like particular phenotypes are selected through evolution and allow organisms to occupy particular ecological niches (Noor \& Milo, 2012; Rotolo \& McPherson, 2001). The idea that individuals select (or are selected into) particular niches is pervasive in theories of intelligence and personality development (Caspi, Roberts, \& Shiner, 2005), and are central tenets of modern transactional models that attempt to clarify the link between individual differences in general psychological traits and the paths and opportunities afforded by the environment (Dickens \& Flynn, 2001). In contrast to the work on strategy selection, the research in this domain has dealt less with the cognitive mechanisms underlying niche selection and more with finding evidence for the role of psychological primitives, such as intelligence and personality, on individuals' educational (Tucker-Drob, Briley, \& Harden, 2013) or occupational trajectories (Woods, Lievens, De Fruyt, \& Wille, 2013).

In what follows, we provide a few examples of recent works that address the importance of such adaptation processes in determining age differences in performance both in laboratory tasks as well as in the wild. Our goal is to showcase similarities between disparate literatures that have adopted an ecological perspective and emphasized the role of strategy or niche selection in individuals' adaptation across the life span. Overall, we believe that uniting these so far relatively independent strands of research promises to clarify how selection processes can help aging decision makers adapt successfully in many life domains.

\section{The Ecological Perspective in the Laboratory}

Past research has provided a good description of age-related decline in core fluid abilities, such as processing speed and 
Table 1. Two selection processes that contribute to individual adaptation

\begin{tabular}{lll}
\hline Selection unit & \multicolumn{1}{c}{ Description } & Exemplary references \\
\hline Strategy & $\begin{array}{l}\text { Individuals have different strategies at their disposal to solve a specific } \\
\text { problem and select these so as to fulfill their goals (i.e., maximize decision } \\
\text { performance) }\end{array}$ & Lemaire (2010); Mata, Pachur, et al. (2012) \\
Niche & $\begin{array}{l}\text { Individuals are faced with different niches (e.g., problems, tasks, } \\
\text { occupations) and select (or are selected) into those in which they best } \\
\text { function (i.e., select and are selected into occupations in which they can } \\
\text { maximize their productivity) }\end{array}$ & $\begin{array}{l}\text { Caspi, Roberts, and Shiner (2005); Gurven } \\
\text { and Kaplan (2006); Kooij et al. (2014) }\end{array}$ \\
& &
\end{tabular}

working memory, from both cross-sectional (Hartshorne \& Germine, 2015) and longitudinal studies (Lindenberger, 2014). Some authors have concluded from the literature on age-related cognitive decline that there is bound to be a negative link between advanced age and performance in disparate domains, claiming, for example, that "just as elders show profound declines in cognitive function, they also show profound declines in choice rationality" (Tymula et al., 2013). However, laboratory work on aging and decision making suggests that broad statements about the link between age-related cognitive decline and performance are unwarranted because task characteristics are crucial in engendering age differences in decision behavior.

A number of studies suggest that the extent to which tasks tap into fluid cognitive abilities, such as learning (Mata, Josef, Samanez-Larkin, \& Hertwig, 2011) and memory abilities (Mata, von Helversen, Karlsson, \& Cüpper, 2012), is a powerful determinant of age differences in judgment and decision making. For example, task complexity, in the form of the amount of information available, is key in creating differences between young and older adults: Studies comparing young and older adults' predecisional information search suggest that when little information needs to be considered, young and older adults show similar behavior; however, once the number of cues (Mata, Schooler, \& Rieskamp, 2007) or objects (Frey, Mata, \& Hertwig, 2015) increases, individual and age differences become apparent and are associated with individual differences in fluid cognitive ability.

Crucially, there is now evidence for different tasks tapping into qualitatively different types of abilities, such as fluid versus crystallized abilities, which show considerably different age gradients. Consequently, different tasks have the potential to generate diametrically opposed effects, with some showing advantages for young adults, and others for older adults. For example, one study tested over 550 individuals from 25 to 80 years on a comprehensive battery of decision making and cognitive measures, including tests of both fluid and crystallized abilities (Del Missier et al., 2013). The results suggest that while some decision tasks, such as those involving the integration of several pieces of information to make a decision, were most strongly correlated with fluid abilities, other tasks, such as avoiding sunk costs, were more strongly correlated with crystallized abilities, with only the former (and not the latter) showing young-age advantages in performance. Another study has shown that crystallized but not fluid abilities are associated with patience and financial literacy, which suggests that knowledge can be an important variable beyond cognitive capacity in determining at least some aspects of financial decision making (Li, Baldassi, Johnson, \& Weber, 2013). As a whole, such findings suggest that different tasks and problems can vary in how they tax either fluid or crystallized abilities and thus lead to either increased or decreased performance in older relative to young adults.

There are a number of outstanding issues related to the laboratory studies discussed above as regards the link between aging and adaptation. First, one question concerns how different facets of fluid abilities, such as processing speed or working memory, can be disentangled to explain age effects in higher-order adaptive behavior (e.g., Lemaire, 2010; Mata, Pachur, et al., 2012). Future laboratory work may make progress on this issue by including evermore fine-grained measures of these abilities and comparing their power to predict individual and age differences in performance in various tasks. Second, and perhaps more importantly, past laboratory work has focused on the role of fluid abilities and, in turn, neglected social skills and domain-specific knowledge that, while possibly harder to quantify in a laboratory context, are also more likely to show increases with advanced age (Scheibe \& Carstensen, 2010) and thus contribute to the variety of age-performance relations across tasks and domains. In the next section, we address how an ecological perspective can be used to understand a broader range of abilities, skills, and knowledge that have implications for real-world performance.

\section{The Ecological Perspective in the Wild}

The world presents decision makers with different challenges that vary from fast-paced decisions on the soccer pitch, the loftier creative and intellectual choices required in the pursuit of science, and the slow weaving of strategic coalitions in business and politics. An ecological perspective 
(A)

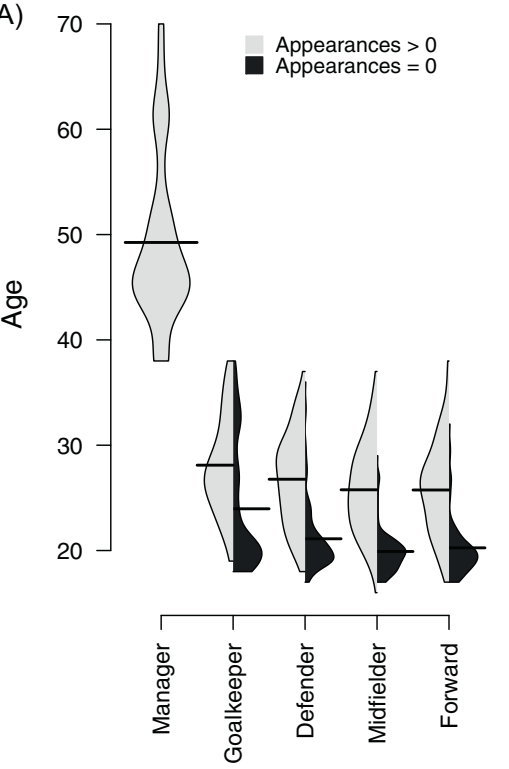

(B)

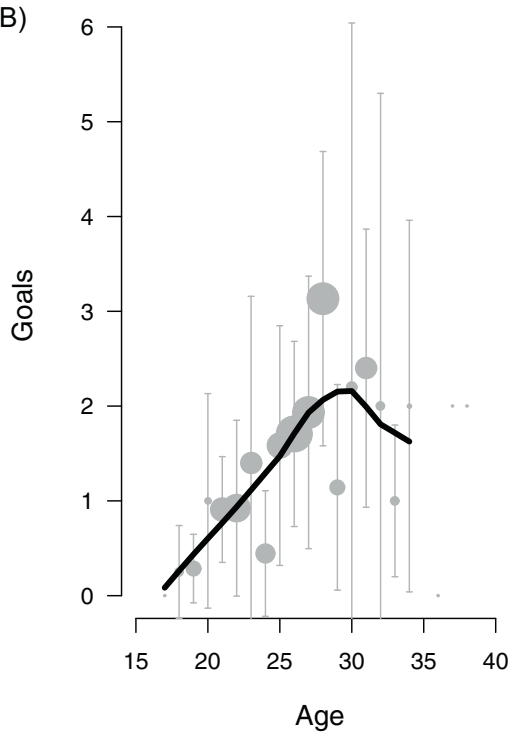

Figure 2. Age distributions and performance in the UEFA Champions League soccer tournament $2014-$ 2015. (A) Manager and player age distributions depending on whether or not they played in the tournament (Appearances $>0$ vs. Appearances $=0$ ). (B) Average goals scored by forwards as a function of age; circle diameters are proportional to the number of individuals in each age bracket; solid lines represent the best-fitting LOESS regression curve; error bars represent 95\% confidence intervals. Data retrieved from http://www.uefa.com and http://wikipedia.org in June 2015. would suggest that, to the extent that such challenges tax abilities differentially affected by aging, they can prove more or less suited to aging decision makers and show different patterns of peak performance (Lehman, 1945; see McDaniel, Presta, \& Banks, 2012, for an overview). For example, performance peaks earlier in physically demanding occupations, such as sports (Figure 2), than in occupations requiring strategic and intellectual thinking, such as politics (Figure 3).

Even within a domain such as sports, however, some tasks (and the respective niches) may be more appropriate to aging individuals. As Figure 2A shows, soccer managers are typically substantially older than players. Moreover, there are systematic differences in age distributions as a function of the position played: on average, goalkeepers are the oldest players and forwards are the youngest. This association between age and player position generalizes across leagues and cohorts (Bloomfield, Polman, Butterly, \& O'Donoghue, 2005). This pattern is an example of different tasks (i.e., soccer positions) posing different challenges to aging individuals: Forwards typically perform much more high-intensity work (Di Salvo et al., 2007) than players such as central defenders (Di Salvo et al., 2007; Mohr, Krustrup, \& Bangsbo, 2003), and goalkeepers seem to have the poorest autonomic cardiac function of all soccer players: their training focuses on anaerobic exercise (Bonaiuto et al., 2012). Interestingly, Figure 2 seems to indicate that increased age is associated not only with losses but also with gains: On average, the youngest players are those who, despite being selected for the squad, make no appearances. The most likely explanation is that managers think they lack either the skills or the experience to make a valuable contribution to the team. Finally, players' age indeed seems to be associated with performance: Using the number of goals scored as a performance measure, one sees that forwards' performance peaks before they reach their 30s, which roughly matches the mean age of players in that position (see Figure 2B).

Professional soccer is a physically demanding occupation. Other occupations rely on intellectual or social abilities, which have different life span trajectories. Figure 3C shows the performance curves of members of the European Parliament, measured in terms of the number of speeches or written declarations produced. In contrast to the performance curve for soccer forwards, these distributions show no conspicuous peaks and relatively gentle age-related slopes (see Figure 3). We use such examples for illustrative purposes, but such comparisons are not new: Various authors have speculated about the characteristics of tasks and occupations that can lead to particular age-related performances, including physical as well as cognitive and knowledge demands (Salthouse, 2012; Simonton, 1997; Skirbekk, 2008; see McDaniel et al., 2012, for an overview). For example, Simonton has suggested that the distinct age-performance curves found for different intellectual occupations (e.g., engineering, mathematics, arts) are due to differences in the levels of innovation and experience required.

Perhaps surprisingly given the theoretical consensus described above, proposals that hypothesize age differences performance as a function of age have so far received scarce or mixed empirical support. For example, meta-analyses have found no evidence for Age $\times$ Occupation Effects on general performance measures across occupations (Ng \& Feldman, 2008) or for age-related decline in creativity in occupations requiring high degrees of innovation (Ng \& Feldman, 2013). Perhaps the main difficulty is the 
(A)

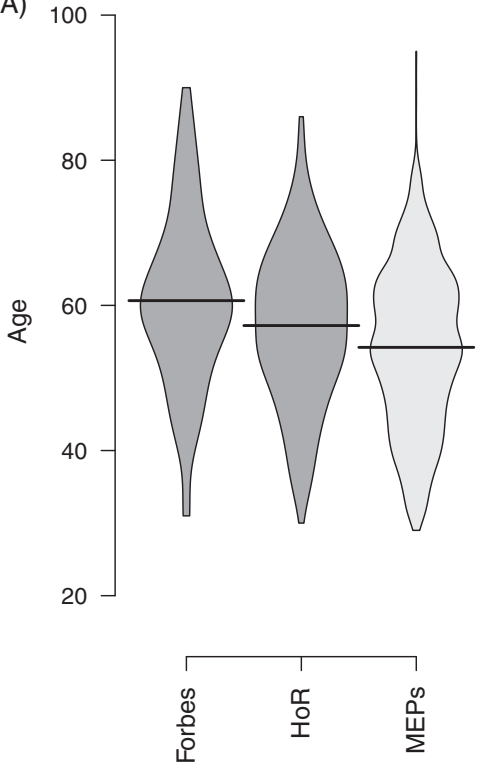

(B)

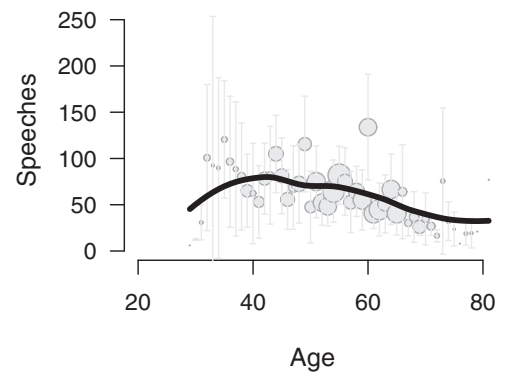

(C)

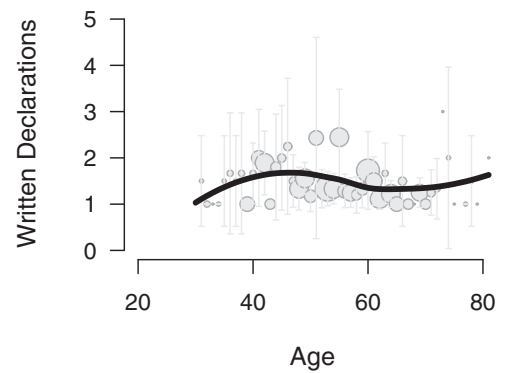

Figure 3. The age distributions of power. (A) Age distributions of individuals listed in Forbes' 2014 ranking of the World's Most Powerful People, members of the U.S. House of Representatives (HoR) in 2015, and Members of the European Parliament (MEPs) in 2015. Average number of MEPs' (B) speeches and (C) written declarations as a function of age. Circle diameters are proportional to the number of individuals in each age bracket; solid lines represent the best-fitting LOESS regression curve; error bars represent $95 \%$ confidence intervals. Data retrieved from http://www. forbes.com, http://wikipedia.org. and http://www.europarl.europa.eu in June 2015. lack of data linking specific task demands to individuals' abilities across the life span. Alternatively, however, the processes of strategy and niche selection that we introduced earlier may be responsible for at least some of the difficulty in identifying age by occupation differences in performance: To the extent that individuals are able to select specific strategies and niches so as to maximize performance, there may be little impact of aging on performance (cf. Mata \& Nunes, 2010; Salthouse, 2012). Recent work in the occupational domain is promising and seems to validate the importance of individuals' efforts in selecting strategies (Kooij et al., 2014) and niches (Wanberg, Kanfer, Hamann, \& Zhang 2015) in the occupational domain. Future work in this area is, however, needed to validate the claim that adaptive strategy and niche selection processes are responsible for continued successful performance in older ages.

In sum, the aging literature has painted broad strokes concerning the psychological and task characteristics that lead to successful performance with increased age (McDaniel et al., 2012). One challenge for the future remains to determine the relative importance of specific strategies used by aging individuals, including how they select (and modify) tasks, goals, and social contacts to improve performance (Kooij et al., 2014). There are further important implications of the ecological approach worth exploring, including the idea that ecologies are not stable. Over time some occupations may become more or less suited to specific skills, for example, as a function of changes in production methods (Autor \& Dorn, 2009), and some authors have proposed that a time dimension is needed to account for the demands for specific skills and abilities across the past decades (Skirbekk, 2008). For example, early studies suggested that aging was associated with declines in academic productivity but more recent studies do not, possibly because of the more collaborative nature of academic work that now allows older scientists to make important contributions later in life (Stroebe, 2010). All in all, only an understanding of the dynamics of both individual abilities and environmental demands will contribute to a holistic view of life span development that is truly embedded in its environmental context as suggested by Bronfenbrenner (1979).

\section{Conclusion}

Despite negative attitudes to aging and the aged, ecological perspectives emphasize the importance of the fit between individual abilities and task characteristics and the possibility of successful performance across the life span in specific domains. We aimed to provide a summary overview of past work adopting an ecological perspective and illustrate the importance of selection processes to performance. Specifically, we argued for the importance of strategy and niche selection processes for individuals' adaptation and successful decision performance. The literature on aging and strategy selection seems to strongly suggest that individuals are able and willing to adapt their strategies to increase the fit between their abilities and challenges faced. In turn, the literature on niche selection is promising but limited in scope, with still much work needed to fully understand the larger issue of how individuals select tasks and occupations.

Our goal was to provide an overview of past work but we also identified important outstanding issues that must be addressed in the future. First, we still know little about the 
extent to which strategy and niche selection effects are selfinitiated and the result of planning. There is some evidence that cognitive limitations may also contribute to constraints in the strategies available to older individuals, which may lead to changes in strategy use that are not the result of adaptive, self-initiated processes (Mata et al., 2007); similarly, the same principle may apply for niche selection because some niches may be imposed by others' biases (North \& Fiske, 2012) rather than selected by oneself. Future work should benefit from distinguishing planned, active selection and other mechanisms in individuals' adaptation to environmental challenges.

All in all, and regardless of the need for future research efforts, we hope that our review illustrates how the ecological perspective can provide a powerful framework to understand adaptation and performance across the life span in many domains, from the foraging challenges of the past to the more familiar ones of modern workplaces.

\section{References}

Autor, D., \& Dorn, D. (2009). This job is "getting old": Measuring changes in job opportunities using occupational age structure. American Economic Review, 99, 45-51. doi: 10.1257/aer.99.2.45

Baltes, P. B., Staudinger, U. M., \& Lindenberger, U. (1999). Lifespan psychology: Theory and application to intellectual functioning. Annual Review of Psychology, 50, 471-507. doi: 10.1146/annurev.psych.50.1.471

Bloomfield, J., Polman, R. C. J., Butterly, R., \& O'Donoghue, P. G. (2005). Analysis of age, stature, body mass, BMI and quality of elite soccer players from 4 European leagues. The Journal of Sports Medicine and Physical Fitness, 45, 58-67.

Bonaiuto, M., Di Mauro, D., Speciale, F., Pagano, F., Buda, D., Magaudda, L., \& Trimarchi, F. (2012). Evaluation of heart rate recovery in relation to playing position in professional soccer players. Journal of Sports Medicine and Physical Fitness, 52, 583-588.

Bronfenbrenner, U. (1979). The ecology of human development: Experiments by nature and design. Cambridge, MA: Harvard University Press.

Caspi, A., Roberts, B. W., \& Shiner, R. L. (2005). Personality development: Stability and change. Annual Review of Psychology, 56, 453-484. doi: 10.1146/annurev.psych.55.090902.141913

Charness, N. (2008). Aging and human Performance. Human Factors, 50, 548-555. doi: 10.1518/001872008X312161

Crimmins, E. M., \& Beltran-Sanchez, H. (2010). Mortality and morbidity trends: Is there compression of morbidity? The Journals of Gerontology Series B: Psychological Sciences and Social Sciences, 66B, 75-86. doi: 10.1093/geronb/gbq088

Del Missier, F., Mäntylä, T., Hansson, P., Bruine de Bruin, W., Parker, A. M., \& Nilsson, L.-G. (2013). The multifold relationship between memory and decision making: An individual-differences study. Journal of Experimental Psychology: Learning, Memory, and Cognition, 39, 1344-1364. doi: 10.1037/a0032379

Diamond, D. W. (1984). Financial intermediation and delegated monitoring. Review of Economic Studies, 51, 393-414. doi: $10.2307 / 2297430$

Dickens, W. T., \& Flynn, J. R. (2001). Heritability estimates versus large environmental effects: the IQ paradox resolved. Psychological Review, 108, 346-369. doi: 10.1037/0033-295X.108.2.346
Di Salvo, V., Baron, R., Tschan, H., Calderon Montero, F., Bachl, N., \& Pigozzi, F. (2007). Performance characteristics according to playing position in elite soccer. International Journal of Sports Medicine, 28, 222-227. doi: 10.1055/s-2006-924294

Frey, R., Mata, R., \& Hertwig, R. (2015). The role of cognitive abilities in decisions from experience: Age differences emerge as a function of choice set size. Cognition, 142, 60-80. doi: 10.1016/ j.cognition.2015.05.004

Gigerenzer, G., \& Gaissmaier, W. (2011). Heuristic decision making. Annual Review of Psychology, 62, 451-482. doi: 10.1146/annurevpsych-120709-145346

Greenfield, E. A. (2012). Using ecological frameworks to advance a field of research, practice, and policy on aging-in-place initiatives. The Gerontologist, 52, 1-12. doi: 10.1093/geront/gnr108

Gurven, M., \& Kaplan, H. (2006). Determinants of time allocation across the lifespan: A theoretical model and an application to the Machiguenga and Piro of Peru. Human Nature, 17, 1-49. doi: 10.1007/s12110-006-1019-6

Gurven, M., Kaplan, H., \& Gutierrez, M. (2006). How long does it take to become a proficient hunter? Implications for the evolution of extended development and long life span. Journal of Human Evolution, 51, 454-470. doi: 10.1016/j.jhevol. 2006.05.003

Hartshorne, J. K., \& Germine, L. T. (2015). When does cognitive functioning peak? The asynchronous rise and fall of different cognitive abilities across the life span. Psychological Science, 26, 433-443. doi: 10.1177/0956797614567339

Hof, P. R., \& Morrison, J. H. (2004). The aging brain: Morphomolecular senescence of cortical circuits. Trends in Neurosciences, 27, 607-613. doi: 10.1016/j.tins.2004.07.013

Kooij, D. T. A. M., Tims, M., \& Kanfer, R. (2014). Successful aging at work: The role of job crafting. In P. M. Bal, D. T. A. M. Kooij, \& D. M. Rousseau (Eds.), Aging workers and the employeeemployer relationship (pp. 145-161). New York, NY: Springer International Publishing.

Lee, R. (2011). The outlook for population growth. Science, 333, 569-573. doi: 10.1126/science.1208859

Lehman, H. C. (1945). "Intellectual" versus "physical" peak performance: The age factor. The Scientific Monthly, 61, 127-137.

Lemaire, P. (2010). Cognitive strategy variations during aging. Current Directions in Psychological Science, 19, 363-369.

Li, S.-C. (2003). Biocultural orchestration of developmental plasticity across levels: The interplay of biology and culture in shaping the mind and behavior across the life span. Psychological Bulletin, 129, 171-194. doi: 10.1037/0033-2909.129.2.171

Li, Y., Baldassi, M., Johnson, E. J., \& Weber, E. U. (2013). Complementary cognitive capabilities, economic decision making, and aging. Psychology and Aging, 28, 595-613. doi: $10.1037 / a 0034172$

Lindenberger, U. (2014). Human cognitive aging: Corriger la fortune? Science, 346, 572-578. doi: 10.1126/science.1254403

Marewski, J. N., \& Schooler, L. J. (2011). Cognitive niches: An ecological model of strategy selection. Psychological Review, 118, 393-437. doi: 10.1037/a0024143

Mata, R., von Helversen, B., Karlsson, L., \& Cüpper, L. (2012). Adult age differences in categorization and multiple-cue judgment. Developmental Psychology, 48, 1188-1201. doi: 10.1037/ a0026084

Mata, R., Josef, A. K., Samanez-Larkin, G. R., \& Hertwig, R. (2011). Age differences in risky choice: A meta-analysis. Annals of the New York Academy of Sciences, 1235, 18-29. doi: 10.1111/ j.1749-6632.2011.06200.x

Mata, R., \& Nunes, L. (2010). When less is enough: Cognitive aging, information search, and decision quality in consumer choice. Psychology and Aging, 25, 289-298. doi: 10.1037/a0017927 
Mata, R., Pachur, T., von Helversen, B., Hertwig, R., Rieskamp, J., \& Schooler, L. (2012). Ecological rationality: A framework for understanding and aiding the aging decision maker. Frontiers in Neuroscience, 6, 19. doi: 10.3389/fnins.2012.00019

Mata, R., Schooler, L. J., \& Rieskamp, J. (2007). The aging decision maker: Cognitive aging and the adaptive selection of decision strategies. Psychology and Aging, 22, 796-810. doi: 10.1037/ 0882-7974.22.4.796

McDaniel, M. A., Pesta, B. J., \& Banks, G. C. (2012). Job performance and the aging worker. In W. C. Borman \& J. W. Hedge (Eds.), The Oxford handbook of work and aging (pp. 280-297). Oxford: Oxford University Press.

Mohr, M., Krustrup, P., \& Bangsbo, J. (2003). Match performance of high-standard soccer players with special reference to development of fatigue. Journal of Sports Sciences, 21, 519-528. doi: 10.1080/0264041031000071182

Ng, T. W., \& Feldman, D. C. (2008). The relationship of age to ten dimensions of job performance. Journal of Applied Psychology, 93, 392-423. doi: 10.1037/0021-9010.93.2.392

Ng, T. W. H., \& Feldman, D. C. (2013). A meta-analysis of the relationships of age and tenure with innovation-related behaviour. Journal of Occupational and Organizational Psychology, 93, 392-423. doi: 10.1111/joop.12031

Noor, E., \& Milo, R. (2012). Efficiency in evolutionary trade-offs. Science, 336, 1114-1115. doi: 10.1126/science.1223193

North, M. S., \& Fiske, S. T. (2012). An inconvenienced youth? Ageism and its potential intergenerational roots. Psychological Bulletin, 138, 982-997. doi: 10.1037/a0027843

Oeppen, J., \& Vaupel, J. W. (2002). Demography. Broken limits to life expectancy. Science, 296, 1029-1031. doi: 10.1126/science. 1069675

Payne, J. W., Bettman, J. R., \& Johnson, E. J. (1993 ). The adaptive decision maker. New York, NY: Cambridge University Press.

Rotolo, T., \& McPherson, J. M. (2001). The Sytem of occupations: Modeling occupations in sociodemographic space. Social Forces, 79, 1095-1130. doi: 10.2307/2675619?ref=no-x-route: 6e406377ed81bfd3de889db90369090d

Salthouse, T. (2012). Consequences of age-related cognitive declines. Annual Review of Psychology, 63, 201-226. doi: 10.1146/annurev-psych-120710-100328

Salthouse, T. A. (2009). When does age-related cognitive decline begin? Neurobiology of Aging, 30, 507-514. doi: 10.1016/ j.neurobiolaging.2008.09.023

Sanderson, W. C., \& Scherbov, S. (2010). Remeasuring aging. Science, 329, 1287-1288. doi: 10.1126/science.1193647

Satariano, W. A. (2006). Epidemiology of aging: An ecological approach. Sudbury, MA: Jones and Bartlet.

Scheibe, S., \& Carstensen, L. L. (2010). Emotional aging: Recent findings and future trends. The Journals of Gerontology Series B: Psychological Sciences and Social Sciences, 65B, 135-144. doi: 10.1093/geronb/gbp132

Simonton, D. K. (1997). Creative productivity: A predictive and explanatory model of career trajectories and landmarks. Psychological Review, 104, 66-89. Retrieved from http://www. infocenters.co.il/lesley/multimedia/14629.pdf

Skirbekk, V. (2008). Age and productivity potential: A new approach based on ability levels and industry-wide task demand. Population and Development Review, 34, 191-207. Retrieved from http://www.jstor.org/stable/10.2307/25434764

Stroebe, W. (2010). The graying of academia: Will it reduce scientific productivity? The American Psychologist, 65, 660-673. doi: 10.1037/a0021086

Tanaka, H., \& Seals, D. R. (2007). Endurance exercise performance in Masters athletes: Age-associated changes and underlying physiological mechanisms. The Journal of Physiology, 586 55-63. doi: 10.1113/jphysiol.2007.141879

Tymula, A., Rosenberg Belmaker, L. A., Ruderman, L., Glimcher, P. W., \& Levy, I. (2013). Like cognitive function, decision making across the life span shows profound age-related changes. Proceedings of the National Academy of Sciences of the United States of America, 110, 17143-17148. doi: 10.1073/pnas. 1309909110

Tucker-Drob, E. M., Briley, D. A., \& Harden, K. P. (2013). Genetic and environmental influences on cognition across development and context. Current Directions in Psychological Science, 22, 349-355. doi: 10.1177/0963721413485087

Walker, R., Hill, K., Kaplan, H., \& McMillan, G. (2002). Age-dependency in hunting ability among the Ache of Eastern Paraguay. Journal of Human Evolution, 42, 639-657. doi: 10.1006/jhev.2001.0541

Wanberg, C. R., Kanfer, R., Hamann, D. J., \& Zhang, Z. (2015). Age and reemployment success after job loss: An integrative model and meta-analysis. Psychological Bulletin, 142, 400-426. doi: 10.1037/bul0000019

Woods, S. A., Lievens, F., De Fruyt, F., \& Wille, B. (2013). Personality across working life: The longitudinal and reciprocal influences of personality on work. Journal of Organizational Behavior, 34, S7-S25. doi: 10.1002/job.1863

Received July 1, 2016

Revision received December 14, 2016

Accepted February 6, 2017

Published online September 7, 2017

\section{Rui Mata}

Center for Cognitive and Decision Sciences

Department of Psychology

University of Basel

Missionsstrasse 60-62

4055 Basel

Switzerland

rui.mata@unibas.ch

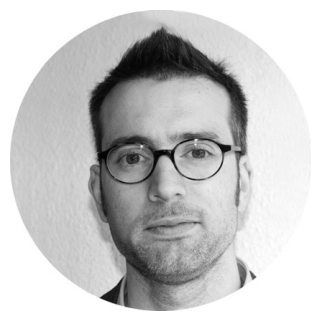

Rui Mata is Assistant Professor for Cognitive and Decision Sciences, University of Basel, Switzerland, and an Adjunct Researcher at the Center for Adaptive Rationality, Max Planck Institute for Human Development, Germany. He studies the life span development of judgment and decision making.

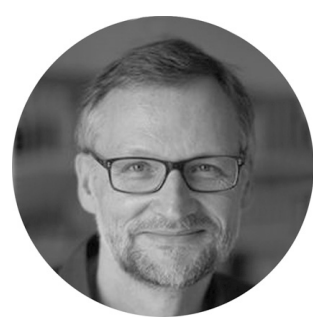

Ralph Hertwig is Director of the Center for Adaptive Rationality, Max Planck Institute for Human Development, Germany, Honorary Professor at Free University of Berlin, Germany, and Honorary Professor at the Humboldt University, Germany. He studies the ecological and social rationality of decision making strategies. 